\title{
Sagittal spino-pelvic parameters of adult isthmic spondylolisthesis
}

\author{
Feng Zhu, Hongda Bao, Shouyu He, Zezhang Zhu, Yong Qiu*, Xu Sun, Zhen Liu, Bin Wang \\ From The 10th Meeting of the International Research Society of Spinal Deformities (IRSSD 2014 Sapporo) \\ Sapporo, Japan. 29 June - 2 July 2014
}

\section{Objective}

To compare the differences of spino-pelvic parameters between patients with isthmic spondylolisthesis of different grades, and to investigate the correlation between L5 incidence angle (L5I) and the percentage of spondylolisthesis.

\section{Methods}

60 patients with L5-S1 isthmic spondylolisthesis (mean age, 47years, range, 28 to 69 years) and age-matched control group of 77 normal adults (mean age, 43.5 years, range, 25 to 63 years) were recruted in this retrospective study. Parameters including slip distance (SD), slipping percentage (SP), pelvic incidence (PI), pelvic tilt (PT), sacral slope (SS), L5 incidence (L5I), lumbar-sacral angle (LSA), lumbar lordosis (LL), sagittal vertical axis (SVA) were measured on the long-cassette standing upright lateral radiographs of the spine and pelvis. Patients with spondylolisthesis were divided into two groups based on slipping percentage : Low grade : group A with $\mathrm{SP}<30$ percent (30 cases of 60$)$ and high grade: group B with SP $>30$ percent (30 cases of 60). Differences in sagittal parameters among groups were analyzed using independent samples t-test, and Pearsons correlation coefficients were used to investigate the relationship between spino-pelvic parameters and SP.

\section{Result}

PI, PT, SS, and LL are larger $(\mathrm{p}<0.05)$ in subjects with isthmic spondylolisthesis than those in the control group, while LSA is significantly decreased. L5I is significantly greater in group B, as compared with control group, while there was no significant difference between group A and control group. Strong positive correlation between the SP and PI, PT, SS, SVA and negative correlation between SP and LSA were confirmed in all the patients

Spine Surgery, Affiliated Drum Tower Hospital of Nanjing University Medical School, China

\section{and take full advantage of:}

- Convenient online submission

- Thorough peer review

- No space constraints or color figure charges

- Immediate publication on acceptance

- Inclusion in PubMed, CAS, Scopus and Google Scholar

- Research which is freely available for redistribution Submit your manuscript at
www.biomedcentral.com/submit C BioMed Central 